\title{
DURAND NEIGHBOURHOOD HERITAGE INVENTORY: TOWARD A DIGITAL CITYWIDE SURVEY APPROACH TO HERITAGE PLANNING IN HAMILTON
}

\author{
V. Angel ${ }^{\mathrm{a}}$, A. Garvey ${ }^{\mathrm{a}}$, M. Sydor ${ }^{\mathrm{a}}$ \\ a ERA Architects Inc, Toronto, ON, Canada - (MikaelS, AngelaG, VictoriaA)@eraarch.ca
}

Commission II

KEY WORDS: heritage inventory, digital documentation, historic urban landscape, citywide survey, inner city, Hamilton, Durand

\begin{abstract}
:
In the face of changing economies and patterns of development, the definition of heritage is diversifying, and the role of inventories in local heritage planning is coming to the fore. The Durand neighbourhood is a layered and complex area located in inner-city Hamilton, Ontario, Canada, and the second subject area in a set of pilot inventory studies to develop a new city-wide inventory strategy for the City of Hamilton,. This paper presents an innovative digital workflow developed to undertake the Durand Built Heritage Inventory project. An online database was developed to be at the centre of all processes, including digital documentation, record management, analysis and variable outputs. Digital tools were employed for survey work in the field and analytical work in the office, resulting in a GIS-based dataset that can be integrated into Hamilton's larger municipal planning system. Together with digital mapping and digitized historical resources, the Durand database has been leveraged to produce both digital and static outputs to shape recommendations for the protection of Hamilton's heritage resources.
\end{abstract}

\section{INTRODUCTION}

This paper presents the digital documentation, analysis, and management methods that were developed for the City of Hamilton's Durand Built Heritage Inventory (the Durand Inventory), carried out by ERA Architects between the spring of 2015 and winter of 2016

The physical and historical complexity of the Durand neighbourhood, and its identity as a place of community-led heritage conservation, make the Durand Inventory a valuable case study for investigating the utility of digital workflows in large-scale heritage survey and inventory work.

\subsection{Durand Neighbourhood}

One of the four original neighbourhoods of Hamilton, Ontario, Durand occupies the southwest quadrant of the city's historic core. The largely residential neighbourhood is bounded on three sides by important thoroughfares and by the face of the Niagara Escarpment at its south end. When the town was established, the topography of the area attracted Hamilton's elites who established picturesque estates within Durand's present boundaries. Although the area developed considerably over time, it has long been perceived as a refuge from the downtown core, in part because of its topography and the richness of its built environment. Durand is an inner city neighbourhood that remains connected to the historic urban core, with a layered urban form that reflects every major era of Hamilton's urban development (Elman, 2001), (Harris, 2015), (Peace, 1996), (Freeman, 2001).

Owing to these conditions, Durand has been home to a highly diverse community and varied residential enclaves throughout its history. It was during the 1970s that the area's identity as a neighbourhood coalesced, when members of its community joined together to call for a more community-based approach to urban planning and stewardship of Hamilton's cultural heritage.
These actions set a new course for neighbourhood planning and heritage conservation across the city and brought about a creative approach to community-led urban development within the neighbourhood.

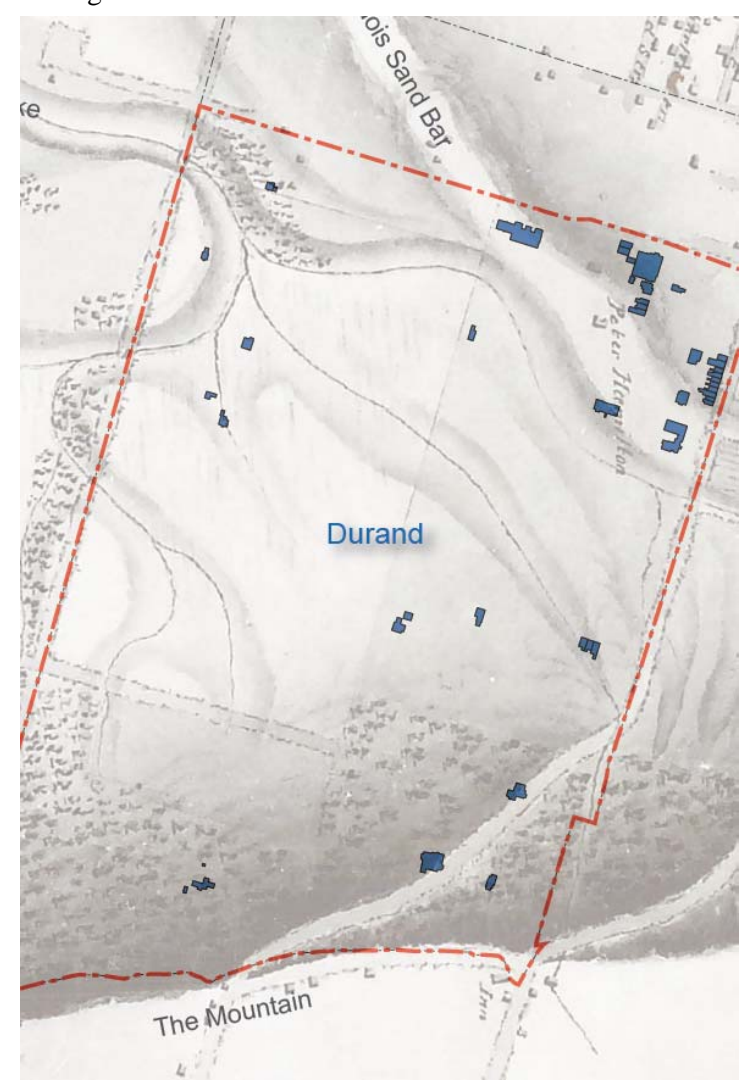

Figure 1. Extant footprints of pre-confederation buildings overlaid on a digitized and projection-corrected 1842 map 


\subsection{Changing role of heritage inventories}

Urban environments and their hinterlands, including Hamilton and the southern Ontario region, are undergoing dramatic transformation as a result of changing economies and emerging patterns of development. Concurrently, a shift has occurred in how historic urban areas are conceptualized. The traditionally siloed realms of nature and culture, tangible and intangible, and people and place are increasingly challenged by the way that we understand and experience the world around us (Harrison, 2015). Rather than being restricted to static artefacts, heritage is now understood to be something that is living, practiced and experienced (UNESCO, 2011). There is a growing concern about social equity and the principle that everyone has a right and responsibility to participate in heritage conservation, and conversely that heritage should benefit all of society (Council of Europe, 2005).

These ideas are influencing practice and giving rise to new techniques and strategies. Survey work is returning to the foreground, with the potential to play an even greater role in shaping urban development in the current age of integrative approaches and big data (Harrison, 2015). Recognizing the changing roles of inventories, the Durand Inventory aimed to refine Hamilton's survey approach and contribute an inclusive, low-cost, contextual inventory strategy to the international dialogue on inventory methodology.

\subsection{Hamilton City-wide Inventory}

The Durand Inventory methodology built upon and refined an approach that was developed for Hamilton's Downtown Built Heritage Inventory (DBHI) pilot project (ERA Architects, 2014). The DBHI was launched by the City of Hamilton to examine how its Inventory of Buildings of Architectural and/or Historical Significance (the municipal Inventory, 1976-2002) could be reviewed and updated at a city-wide level. The City is developing a city-wide approach to its Built Heritage Inventory in response to a 2008 planning report (PED08053), which concluded that the municipal Inventory serves as a key tool in heritage conservation planning and management in Hamilton, and should be maintained and updated on an ongoing basis. The current approach aims to address uneven inventory coverage within Hamilton's current municipal boundaries and varied documentation and assessment approaches between properties, which range from tombstone surveys to detailed assessments. Hamilton's city-wide Inventory update also aims to support municipal urban and heritage planning initiatives through the creation of a 'living' inventory process, rather than a static document that captures a moment in time.

At the heart of the DBHI and Durand Inventory approach is the recognition that built heritage resources contribute to the city in many ways. They may be valued for their historical, cultural or architectural significance or for the contribution they make to their historic context and neighbourhood character. Property assessments therefore must be based in a framework that begins with analysis of the subject area's historic context, in order to understand the role built resources play in establishing or supporting neighbourhood character, qualities and attributes. The development of Historic Context Statements for Downtown Hamilton and Durand have helped guide individual property evaluations in each study area.
The DBHI pilot project resulted in Hamilton's City Council approving the adoption of a new approach for reviewing and updating the municipal Inventory at a city-wide level, and approving the listing of over 660 properties on the Municipal Heritage Register and the identification of 30 candidates for designation under the Ontario Heritage Act (City of Hamilton, 2016).

\section{THE DURAND INVENTORY}

\subsection{Approach}

The Durand Inventory expanded the application of the pilot DBHI framework to an additional 1000 built resources, which together comprise the richly varied urban form of the neighbourhood. The approach to field work in Durand was enhanced and streamlined through the development of a mobile survey application that was used, along with other tablet applications, to support documentation and assessment work in the field. Development of the Durand Inventory approach was an opportunity to explore efficient data management options to meet the imperatives of Hamilton's city-wide Inventory update. Emphasis shifted from detailed, intensive-level surveys to reconnaissance-level surveys, and from a selective to an inclusive inventory approach. This provided the impetus for the development and practical use of digital tools and a prototype for efficient documentation, data management and analysis that can be applied at a city-wide scale.

\subsection{Heritage Conservation Process}

This paper describes a built heritage inventory project, therefore, in the larger conservation process the workflow has been applied to the identification of built heritage and recommendations for protection. With the Durand Inventory, we applied the digital workflow to all aspects of inventory work. Specifically, the digital workflow included background research and assembling data, defining boundaries, survey fieldwork, property assessments, review and analysis, and inventory output. The areas where the digital workflow was most innovative was during the field survey and the review and analysis phases of the inventory. The online database tool allowed for a reduction of repetitive tasks, instantaneous access to additional property information and an interactive quality control and review process.

\subsection{Methodology}

In order to understand the origins, evolution and historic patterns that define Durand, the project began with identification of key themes and milestones that shaped the neighbourhood's urban development and relationship to the rest of Hamilton based on a review of primary and secondary sources and previous heritage studies. An extensive review of historic maps of the study area enabled an analysis of the evolution of Durand and its historic resources, with respect to their age, form, and patterns of development. This resulted in the development of an historic context statement for Durand.

Wherever possible, we digitized physical resources such as historical maps and photographs from public archives and supplied by the Durand Neighbourhood Association. Previous individual property evaluations and other relevant research documents were digitized and supplied by City staff. These background resources were uploaded to a cloud-based folder 
and indexed by street address, making them available for reference in the field during the survey process through the use of a tablet.

The study boundaries were proposed by the City to match their current ward divisions. The Durand neighborhood developed from the original Hamilton town site as one of the city's first four wards. The neighbourhood boundaries are still legible, and are reflected in historic plans, maps and contemporary planning documents. We confirmed the suitability of the Durand boundaries using Geographic Information Systems (GIS) to overlay current and historical mapping.

One of the aims of this project was to develop a flexible database that could accommodate the existing data, host the new survey information, and provide appropriate exports to incorporate the data into the inventory. The existing data available from the city consisted of two streams: previous heritage inventory records, and data used to identify real property for taxation. We worked with the city to join the information, and went through a vetting process to consolidate duplicate records. For convenience, we retained the tax roll number as the unique identifier for each record. The city also provided GIS parcels, road allowances and building footprints.

We licensed a commercial database hosting platform (Zoho Creator) and began refining an interface to review the information, add additional records, add or revise fields, and populate information to the fields. The online interface also served as a portal during fieldwork to input and review data. For the fieldwork, we chose a form interface which incorporated various input types including text based, single and multiple selections and a field to upload photos taken in the field. We called this interface the Survey Form.

Development of the Survey Form, to be used to complete the documentation and preliminary assessment of each property, was a key element of the inventory process. The final Survey Form allowed for a reconnaissance-level survey to be developed. A reconnaissance-level survey provides a preliminary review of all built resources within a defined area, and is used to identify, document and report the existence of historic resources. In this phase, only basic information is collected and documented, such as address, date and type. A reconnaissance-level survey does not include detailed historical research or architectural analysis. It provides a baseline of information about all built resources within a study area, it allows for the identification of broad historical patterns, and it helps to identify properties or groups of properties that may merit more detailed research and investigation, in a highly efficient manner.

We referenced paper forms that were in use for previous surveys, including those specific to Hamilton - the Hamilton LACAC Municipal Heritage Committee, and those employed for the Canadian Inventory of Historic Buildings (CIHB). Also included were fields that addressed the criteria outlined under the Ontario Heritage Act and Ontario Regulation 9/06, which provided transparency and defensibility for the inventory's property classification process. Further to these preliminary assessment fields, we also developed specific survey questions to confirm and explore thematic contexts of immediate interest in Durand, for instance the pattern of converting single-family homes to multi-unit dwellings in all character areas. The Survey Form aimed to balance rigorous and defensible heritage planning documentation with inclusive identification of broader historic themes. While the report and study involved community consultations, historic research, walking interviews and peer-review, the survey was the only element to be applied on a property-by-property basis in the study area.

Initially, there were nearly one thousand records associated to properties in our online database, although throughout the survey we identified several more. We included all base information that was made available through taxation information and the City's Planning Department input, including street address, previous studies and existing heritage status. This information was visible in the form interface as prepopulated fields, in order to increase efficiency in the field. A draft Survey Form was tested in the field to calibrate the workflow and outputs of the process for several dozen properties. Several modifications to the content and interface of the Survey Form were made prior to rolling-out to the entire survey. At this stage, we linked the database to our GIS system, enabling mapping of the existing information and the early results.

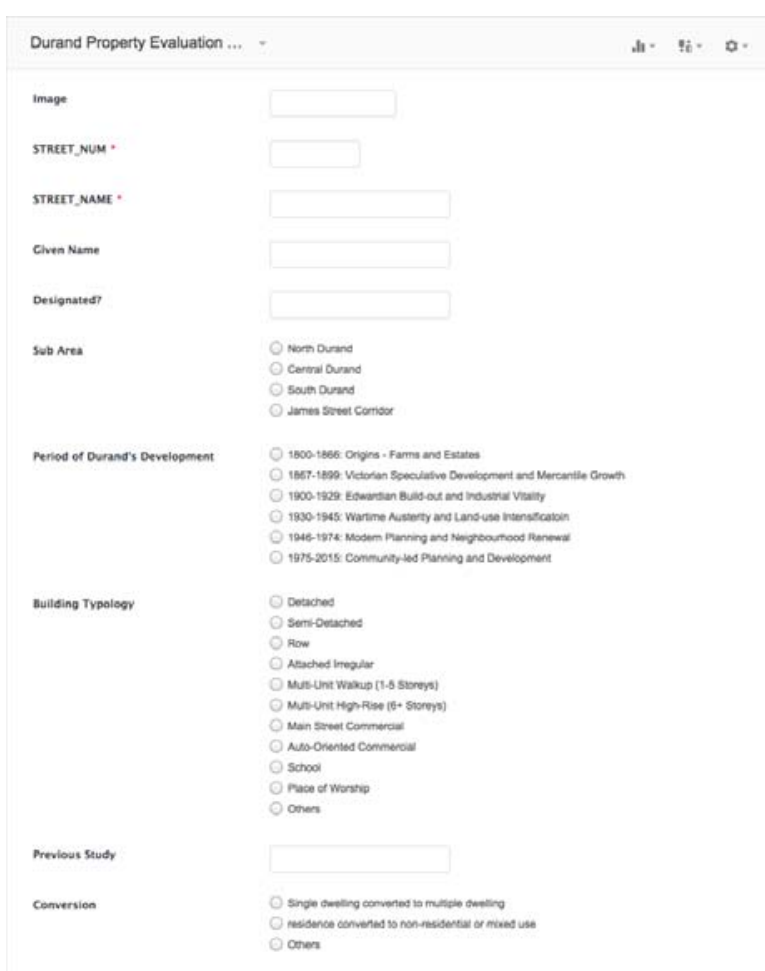

Figure 2. Tablet screen capture of Survey Form interface

\subsection{Fieldwork:}

The survey was completed, as weather permitted, during the summer of 2015. All aspects of the fieldwork were conducted using a tablet (Figure 2). The tablet was tethered to a smart phone mobile hotspot carried by the surveyor, allowing access to materials that were hosted on a cloud server, as well as instant upload of documentation photographs and other survey data collected in the field. The process at each property was to photograph the front elevation of the structure, review relevant information available for the property (previous heritage survey forms, studies, and historic photographs), and input responses on the Survey Form. During this phase, a preliminary 
assessment of the property's contribution to its sub-area context was entered.

In the design of the digital database tool, we also included a feedback/quality control feature that allowed the reviewer to either flag the property for further review, indicate assumptions made, or provide comments for other team members. As the input was live, this permitted instantaneous review for the team members not in the field.

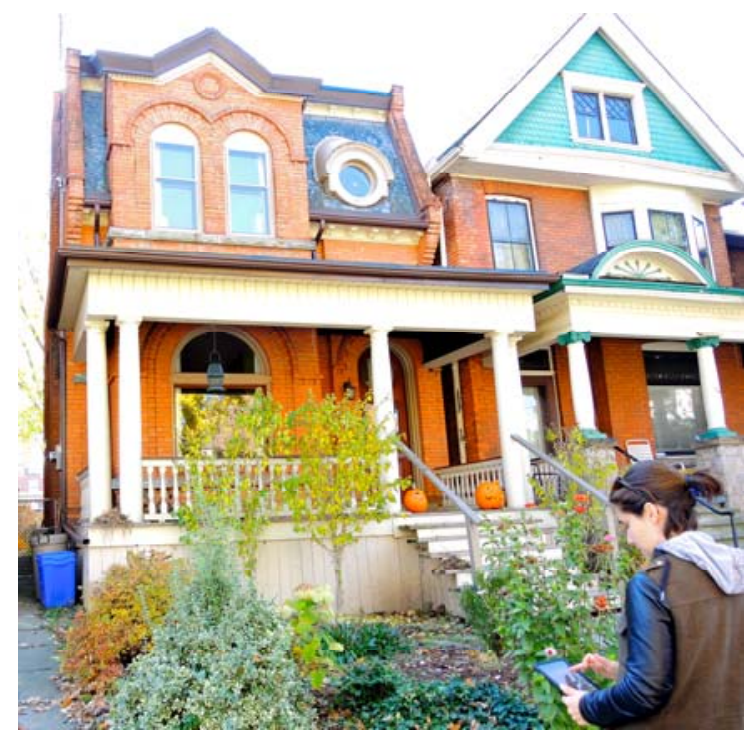

Figure 3. Surveyor using tablet survey app in the field

\subsection{Interim Analysis and Review:}

An essential aspect of the survey process is consistency of documentation and assessment. We employed a multi-tiered review of each property's Inventory evaluation. The first tier was the survey assessment, often followed-up by a second review if the property was flagged in the initial survey. The second tier was a peer-review conducted in the office, based upon the documentation provided by the survey and augmented by additional resources and interim mapping. The first two tiers were done digitally, with different users accessing the online database collaboratively. The third tier was a review by City of Hamilton staff, based on a draft report of findings including preliminary Inventory classifications.

As more and more properties were surveyed and added to the inventory, a wealth of information that permitted a different scale of analysis. Some of the questions on the Survey Form were used to study key aspects that illustrated the morphology of the neighbourhood, and the historic forces that shaped its development. By exporting the online database to a GIS system, we could map the results of any of the questions included in our Survey Form. When various questions were plotted in conjunction, a rich story became evident. For instance, the Durand neighbourhood is composed of a subtle series of higher planes and lower valleys, terminating in the striking Niagara Escarpment. When the extant footprints of pre-confederation buildings were plotted against the topography, it was immediately evident they formed a pattern of "building on the high ground." When we overlaid a digitized and projectioncorrected 1842 map that included former rivers and streams, the pattern was reinforced (Figure 1).
Other analytical maps illustrated the diversity in the block-byblock scale of building footprints by correlating construction dates, conversion of single-family to multi-tenant dwellings, and built-form typology. This scale of analysis, from the finegrained individual building to investigating larger patterns, was permitted by the efficiency of data management and the flexibility of output of our system.

Background research in conjunction with GIS mapping enabled the identification of four sub-areas within the neighbourhood. Each sub-area reflects the broader patterns of the Durand neighbourhood, but has been shaped by a specific set of development patterns, uses and activities, resulting in a distinct set of attributes (features, qualities, characteristics, and patterns of use). Most areas within Durand are characterized by the existence of buildings of varied scales, styles and eras coexisting cheek-by-jowl on the same block (Figure 3), which made the identification of sub-areas challenging, since boundaries are sometimes blurred and appear to overlap. Research and field investigations helped to refine the boundaries of sub-areas.

The inclusion of a sub-area scale of study permitted the documentation of heritage values that were best described beyond the scale of individual property lines and within the scale of the larger neighbourhood. These values manifested themselves as streetscapes, composition of urban form and visual relationships. Presenting Durand as an area composed of distinct sub-areas also appeared to enrich community dialogue during engagement activities.

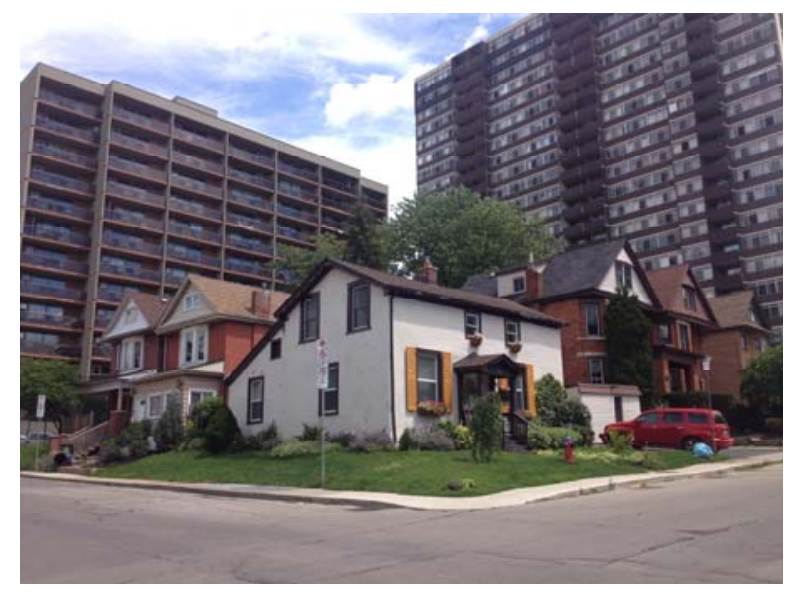

Figure 4. Varied building styles, scales and eras in Durand

\subsection{Outputs:}

Following completion of each of the property evaluations, and analysis and review of the data, the primary output of the project was a report provided to the City of Hamilton. The report presents the three main components of the Durand Built Heritage Inventory, namely the study methodology, Durand's Historic Context Statements, and the results of the Inventory evaluations. In order to structure the recommendations of the report in a format that was translatable to the current municipal planning tools, we proposed a context-based evaluation and classification of each property. Following preliminary assessment, each property within Durand was classified according to its contribution to its context. The classification 
scheme was designed to identify properties that are historical, aesthetic, or cultural landmarks of considerable heritage value (Significant Built Resources), as well as those whose heritage value lies primarily in the contribution they make to their historic context (Character-Defining Resources and CharacterSupporting Resources). Properties that were not considered to be currently contributing to the historic context of Durand were classified as Inventory Property, while those that were found to no longer contain a structure were recommended for removal from the municipal Inventory (Remove from Inventory). Therefore, every building in Durand is now included and has been classified within the City's updateable Inventory database for the area.

In preparation of the final report, GIS mapping was the primary tool for illustrating and summarizing findings. Maps were included in the body of the report and in an exhaustive appendix.

The built heritage Inventory that was included with the report compiled the data in multiple formats:

- $\quad$ Single page summaries of each property including all record fields

- A summary table that included each record, but did not include confidential (taxation) information for public release

- $\quad$ Various spreadsheet and database exports for different audiences within the City

- $\quad$ Maps (for illustrative purposes, and also for inclusion in City documents - Figure 4)

The online database created for this case study was only used for the survey, analysis and production of the report. Following the report, the database was exported in a format that was defined by the City. The information was incorporated into their proprietary planning database and will be maintained as part of their inventory. The inventory will be updated as queries, applications and approval is granted for modifications to individual properties. The city identifies wholesale updating to the citywide inventory every ten years as part of their Cultural Heritage Management Plan.

\section{RESULTS}

ERA assessed and classified 988 properties to be retained on the Inventory, of which 91 were previously designated under the Provincial Heritage Act. The report recommended an additional 746 properties be listed or designated on the Heritage Register due to their evaluations as Significant Built Resources, Character-Defining Resources, and Character-Supporting Resources. The City has indicated ongoing support for the methodologies refined and developed during this study and plans to continue updating the Inventory on a neighbourhoodby-neighbourhood basis.

\subsection{Innovations}

As this study was a continuation of a methodology established with the Downtown Hamilton Built Heritage Inventory (DBHI), the workflows can be directly compared. The DBHI was a paper-based workflow, where the survey was completed by hand in the field, and later digitized for analysis and use in the report. The report outputs were compiled using spreadsheet and vector-based illustration software. We estimate the time spent on the Durand survey and data entry was approximately half that of the DBHI. Benefits of our workflow include the reduction of duplicate work, improved quality control and oversight, and ease-of-use. Additionally, we believe the depth of analysis through GIS integration and data management allowed a deeper and more thorough understanding of the neighbourhood.

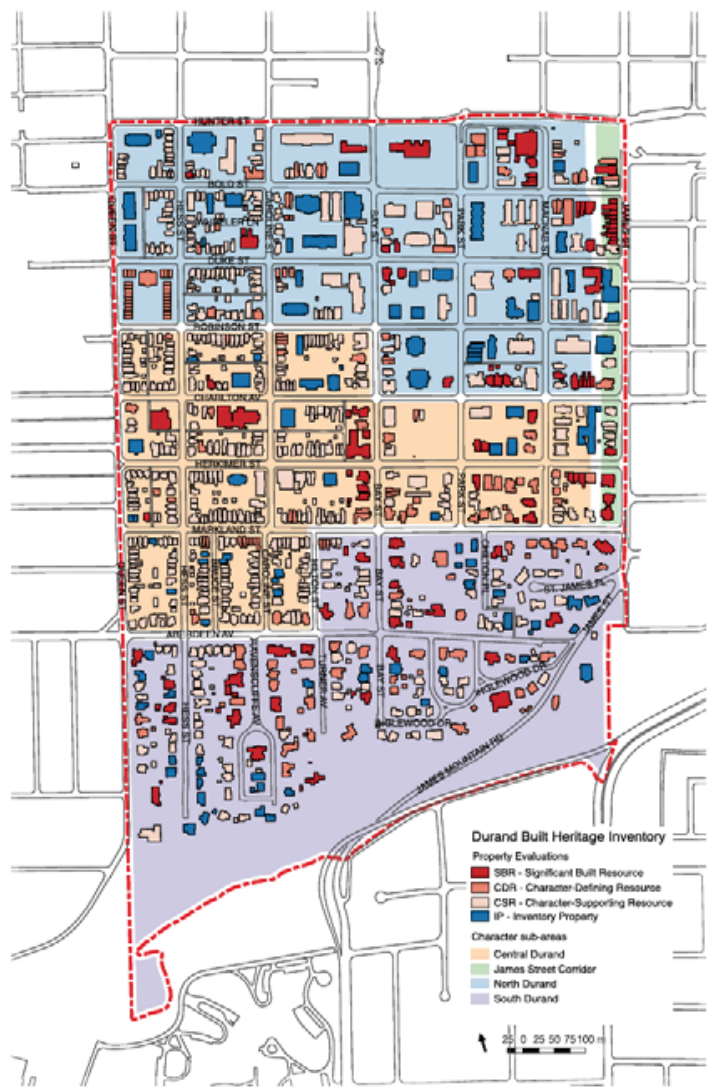

Figure 5. Sub Area and Property Classification Results Map

\subsection{Future Improvements:}

As this was a prototype, we have identified some limitations and improvements for future iterations of the workflow. One of the limitations of this workflow included the lack of ability to work off-line, which would make it not suitable for areas without adequate mobile data coverage. Secondly, we relied upon high-quality existing GIS base files. Survey and production of these files would represent a significant departure from this workflow. Furthermore, as each municipality and region has developed its own methods and standards for GIS data, this workflow is not directly applicable elsewhere without modification and expertise using GIS. Working with technology in the field has limitations of operating temperature and conditions, but perhaps these limitations also apply to the technology's operators.

In future iterations of this workflow we anticipate further development of online features and integration of information gathered via community consultation to the digital workflow. City staff managed an online community survey throughout the study process, however this could be enhanced through online engagement with the process and findings, allowing for a twoway conversation between the community and decision-makers. 
The integration of live mapping is the next logical step for the future development of the online database. The workflow outlined in this paper required the download of a snapshot of the online database in order to join it to static GIS files on a local computer. While they could be updated sequentially, the process was not automated.

Additionally, we recognize the larger potential for a digital inventory workflow to further integrate community consultation and feedback. Our study included several "offline" community consultations meetings that resulted in materials that were integrated in the report. Some of the most effective tools for engagement were hand drawn cognitive maps of the neighbourhood, and the identification of landmarks using pins on a map. We feel that these tools and others would translate well to an online environment and would facilitate outreach to a wider audience.

\section{REFERENCES}

City of Hamilton, 2016. "Hamilton Built Heritage Inventory Process: Recent Inventory Work”. Hamilton City Planning. https://www.hamilton.ca/city-planning/heritage-

properties/hamilton-built-heritage-inventory-process (1 Feb. 2017).

Council of Europe, 2005. "Council of Europe Framework Convention on the Value of Cultural Heritage for Society". $\begin{array}{lll}\text { Treaty Series } & \text { No. }\end{array}$ https://rm.coe.int/CoERMPublicCommonSearchServices/Displa yDCTMContent?documentId=0900001680083746 (1 Feb. 2017).

Elman, R., 2001. Durand: A Neighbourhood Reclaimed. NA Group, Hamilton.

Freeman, B., 2001. Hamilton: A People's History. James Lorimer and Company Publishers, Toronto.

Harris, R. et. al., 2015. A City on the Cusp: Neighbourhood Change in Hamilton since 1970. Paper. Neighbourhood Change Research Partnership, Toronto.

Harrison, R., 2015. Beyond 'Natural' and 'Cultural' Heritage: Toward an Ontological Politics of Heritage in the Age of Anthropocene. In: Heritage \& Society. 8:1, pp. 24-42.

Peace, W. 1996. People, Space and Time: Landscape Changes in Hamilton's Durand Neighbourhood, 1946-1994. Doctoral Dissertation, McMaster University, Hamilton, Ontario.

UNESCO, 2011. "Recommendation on the Historic Urban Landscape, including a glossary of definitions". http://portal.unesco.org/en/ev.phpURL_ID=48857\&URL_DO=DO_TOPIC\&URL_SECTION=20 1.html (1 Feb. 2017). 